\title{
Synthesis of dark brown single-walled carbon nanotubes and their characterization by HSQC-NMR
}

\author{
RAHEBEH AMIRI $^{\mathrm{a}, *}$,HAMIDREZA RAFIEE ${ }^{\mathrm{a}}$, ASHKAN GOLSHANI $^{\mathrm{b}}$ and \\ FIROOZEH CHALABIAN ${ }^{\mathrm{C}}$ \\ ${ }^{a}$ Department of Chemistry, Central Tehran Branch, Islamic Azad University, Tehran 1465613111, Iran \\ ${ }^{b}$ Department of Biology, Carleton University, Ottawa, Ontario K1S 5B6, Canada \\ ${ }^{c}$ Department of Biology, Islamic Azad University, Tehran North Campus, Tehran 1667934783, Iran \\ e-mail: rahebeha@gmail.com; Rah.Amiri@iauctb.ac.ir
}

MS received 20 April 2012; revised 4 August 2012; accepted 22 August 2012

\begin{abstract}
We report here a simple and effective approach to the covalent attachment of single-walled carbon nanotubes (SWCNTs) and azo compounds. The functionalized SWCNTs prepared (through a radical mechanism) have been used for a diazonium coupling reaction. The results showed that the chemical method used has improved the processability and solubility of the carbon nanotubes. The dark brown SWCNTs obtained which can produce a yellow colour in organic solvents were characterized by different spectroscopic analyses. Heteronuclear single quantum coherence spectra $\left({ }^{13} \mathrm{C}-{ }^{1} \mathrm{H} \mathrm{HSQC}\right)$ have been used to detect the carbon nanotube allylic protons. The morphology of the main product has been shown by scanning electron microscopy (SEM).
\end{abstract}

Keywords. Carbon nanotubes; heteronuclear single quantum coherence spectra; covalent attachment; azo compound.

\section{Introduction}

Carbon nanotubes (CNTs) which have been proved to be a novel type of nanostructure with remarkable chemical, electrical and mechanical properties, ${ }^{1,2}$ were being first described by Iijima. ${ }^{3}$ Inspite of the carbon nanotube applications in various fields of science and technology are found, their solubility is one of the remaining challenges. Consequently, a simple and high yield processing functionalization is needed to compensate this deficiency. There are two main approaches for the surface modification of CNTs. The first one is noncovalent functionalization ${ }^{4}$ and the second one is the molecules' covalent attachment to the carbon nanotube walls. ${ }^{5}$ Among these effective reactions, diazonium coupling to CNTs could be the most popular chemical route for the covalent functionalization of carbon nanotubes. On the other hand, azo compounds are one of the most important commercial and industrial compounds for paints, textiles, plastics and metal surface. ${ }^{6-9}$ Also, they play an important role in other practical uses such as biological reactions, ${ }^{10}$ optical storage technologies ${ }^{11}$ and photo electronic effects. ${ }^{12-14}$ In the most cases, azo compounds should be in solid state, but their intrinsic tendency towards aggregation ${ }^{15}$ is a

*For correspondence major technical barrier which nanometerization process could resolve it. ${ }^{16}$ So in the present research, we used the covalent binding of diazonium salt to the functionalized single-walled carbon nanotubes (SWCNTs). It can produce coloured SWCNTs with high solubility and also improve the property of azo dyes or pigments. The main goal of this work is the use of NMR to specify the carbon nanotube protons.

\section{Experimental}

\subsection{Materials}

SWCNTs (Nanotimes Co., Chengdu, China, Purity $>90 \%$ ) which have purified as described in the literature, ${ }^{17}$ are known to have small diameter $(\sim 1 \mathrm{~nm})$ and high purity $(<0.1$ at. $\%$ of residual metal). All the reagents and solvents were purchased from Merck and Aldrich.

\subsection{Characterization}

The resulting mixtures were sonicated in QS 10 ultrasonic bath. The electronic spectra of the products were investigated on an ultraviolet-visible-near infrared (UVVis-NIR) spectrophotometer V570 Jasco. Fourier transform infrared (FTIR) spectra (in $\mathrm{KBr}$ pellets) were 


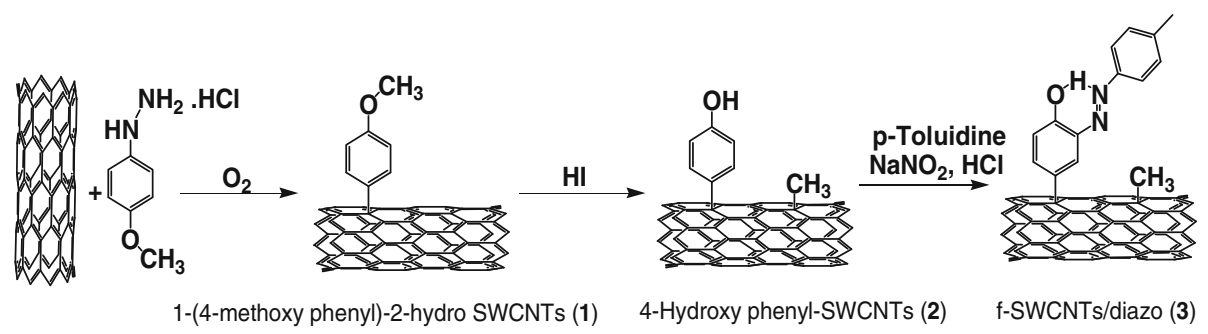

Figure 1. Schematic of chemical reactions on SWCNTs.

recorded on a Perkin-Elmer 1605 FTIR spectrometer. Raman spectra of the samples were recorded on an Amelga Thermo Nicolet Dispersive Raman spectrometer. Scanning electron microscopy (SEM) was performed on XL-30 Philips instrument. The nuclear magnetic resonance (NMR) spectrum was carried out on a Bruker AVANCE $500 \mathrm{MHz}$ with a z-gradient triple resonance probe in ${ }^{13} \mathrm{C}-{ }^{1} \mathrm{H}$ HSQC experiment. The spectral widths were $5000 \mathrm{~Hz}$ and $25000 \mathrm{~Hz}$ for the ${ }^{1} \mathrm{H}-$ and ${ }^{13} \mathrm{C}$-dimensions, respectively. The number of collected complex points was 2048 for ${ }^{1} \mathrm{H}$ - dimension with a recycle delay of $5 \mathrm{~s}$. The number of transients was 64 , and 256 time increments were always recorded in ${ }^{13} \mathrm{C}$ dimension. The ${ }^{1} J_{\mathrm{CH}}$ used was $140 \mathrm{~Hz}$. The $J$-coupling evolution delay was set to $3.2 \mathrm{~ms}$. DMSO- $d_{6}(\delta \mathrm{c} 39.5$; $\left.\delta_{\mathrm{H}} 3.35 \mathrm{ppm}\right)$ and $\mathrm{CDCl}_{3}\left(\delta \mathrm{c} 77.4 ; \delta_{\mathrm{H}} 7.29 \mathrm{ppm}\right)$ were used as solvents and TMS as an internal reference.

\subsection{4-Hydroxy phenyl-SWCNTs (2) preparation}

In a typical experiment (figure 1), purified SWCNTs were functionalized with 4-methoxy phenyl hydrazine hydrochloride in the presence of air oxygen through a free radical addition process ${ }^{18}$ to give 1-(4-methoxy phenyl)-2-hydro SWCNTs 1. The product obtained (10 mg, containing $1.67 \mathrm{mmol}$ functional group) was sonicated with $30 \mathrm{ml}$ dimethylformamide (DMF) for $30 \mathrm{~min}$ and was refluxed at $153^{\circ} \mathrm{C}$ in the presence of $\mathrm{HI}$ (211.2 $\mathrm{mg}, 1.65 \mathrm{mmol}$ ) for $3 \mathrm{~h}$, after that, the mixture was filtered through a polytetrafluoroethylene (PTFE) membrane (pore size $0.2 \mu \mathrm{m}$ ). The final product was washed with methanol $(100 \mathrm{ml})$ and 4-hydroxy phenylSWCNTs 2 collected $(10 \mathrm{mg})$ were dried in vacuum at $80^{\circ} \mathrm{C}$ for $12 \mathrm{~h}$.

\section{$2.4 f$-SWCNTs/diazo compound (3) preparation}

The resulting f-SWCNTs 2 (10 mg, containing $1.67 \mathrm{mmol}$ phenoxyl functional group) were sonicated for $30 \mathrm{~min}$ with DMF $(30 \mathrm{ml})$ to get a visually homogeneous suspension.
Fine powdered $\mathrm{NaNO}_{2}(125.0 \mathrm{mg}, 1.67 \mathrm{mmol})$ was added slowly and with stirring to the mixture of 4methyl aniline $(178.8 \mathrm{mg}, 1.67 \mathrm{mmol}), \mathrm{HCl}(0.5 \mathrm{ml})$ and $\mathrm{H}_{2} \mathrm{O}(3 \mathrm{ml})$. Temperature must be below $5^{\circ} \mathrm{C}$. The solution was then added drop-wise to the primary suspension of f-SWCNTs 2 and $\mathrm{Na}_{2} \mathrm{CO}_{3}(212.0 \mathrm{mg}, 2.0 \mathrm{mmol})$ in $\mathrm{H}_{2} \mathrm{O}(5 \mathrm{ml})$. After stirring for $1 \mathrm{~h}$, the nano azo product 3 was filtered and washed with $\mathrm{H}_{2} \mathrm{O}$ until the filtrate become colourless. The f-SWCNTs/diazo 3 was dried in vacuum for $36 \mathrm{~h}$ before characterization (figure 1).

\section{Results and discussion}

\subsection{Characterization of carbon nanotubes}

3.1a UV-Vis-NIR spectra: The ultraviolet-visiblenear infrared (UV-Vis-NIR) adsorption spectra of 4hydroxy phenyl-SWCNTs 2 and f-SWCNTs/diazo 3 $(0.2 \mathrm{mg} / \mathrm{ml})$ have been shown in figure 2 . Since we wanted to show the ability to produce colour of the main product, so we have gotten UV spectrum in visible region. While, the used van Hove singularities in the semiconducting nanotubes are centered at about $800-1400 \mathrm{~nm}$ and the band at about $500 \mathrm{~nm}$ for the metallic tubes can be less distinct and does not appear. Dark brown f-SWCNTs/diazo 3 is soluble in chloroform or other organic solvents and gives yellow liquor. It has a maximum absorption at $340 \mathrm{~nm}(\log \varepsilon=2.30)$ corresponding to the $\pi \rightarrow \pi^{*}$ transition of transazobenzene. Whereas, 4-hydroxy phenyl-SWCNTs 2 is not soluble in $\mathrm{CHCl}_{3}$ and it has not shown any maximum absorption.

3.1b FTIR spectra: Fourier transform infrared (FTIR) spectroscopic analysis of 4-hydroxy phenylSWCNTs 2 and f-SWCNTs/diazo $\mathbf{3}$ confirms the presence of $\mathrm{C}-\mathrm{N}\left(1027 \mathrm{~cm}^{-1}\right), \mathrm{N}=\mathrm{N}\left(1430 \mathrm{~cm}^{-1}\right)$, $\mathrm{C}=\mathrm{C}\left(1641 \mathrm{~cm}^{-1}\right)$, aliphatic and aromatic $\mathrm{C}-\mathrm{H}(2854$ $\left.3000 \mathrm{~cm}^{-1}\right)$, and $-\mathrm{OH}\left(3427 \mathrm{~cm}^{-1}\right)$ functional groups at the surface of SWCNTs. In the case of 4-hydroxy phenyl-SWCNTs $\mathbf{2}$, some of the mentioned peaks were 

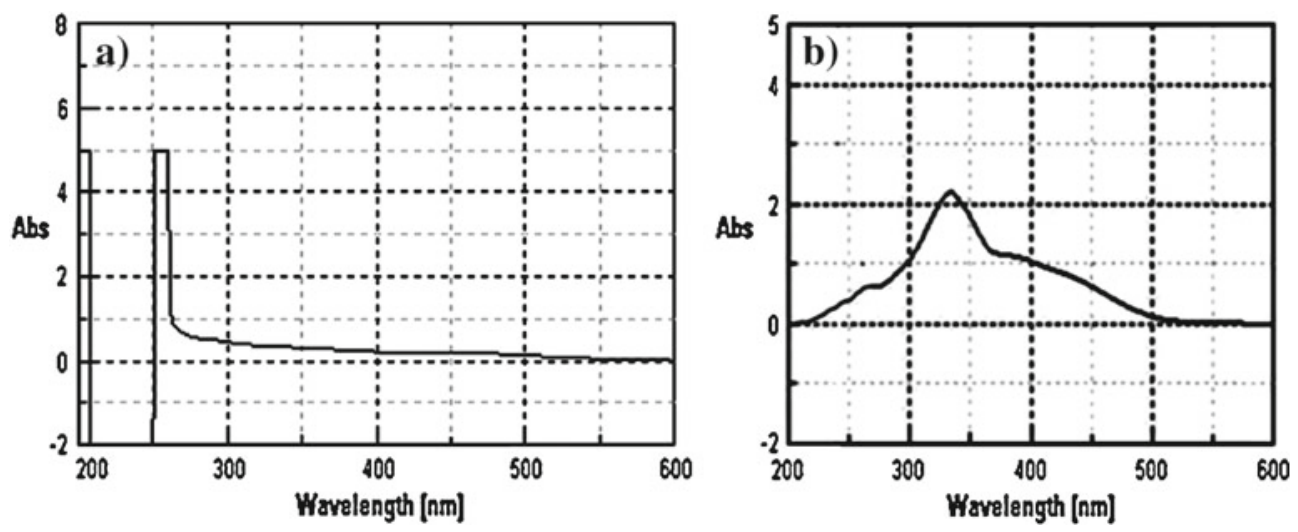

Figure 2. UV-Vis spectrum of (a) 4-Hydroxy phenyl-SWCNTs 2, (b) f-SWCNTs/diazo 3.

found in FTIR spectrum of it with lower intensity and a bit shift. Consequently, the characteristic bands of the final product $\mathbf{3}$ might overlap with the features of precursor 2 (figure $\mathrm{S} 1$ ).

3.1c Raman spectra: Raman spectroscopy has been extensively used to probe the structural and electronic properties of carbon nanotubes. The most important bands in Raman spectra of f-SWCNTs/diazo 3 are the strong $\mathrm{G}$ band at $1582 \mathrm{~cm}^{-1}$ which ascribed to the in-plane $\mathrm{C}-\mathrm{C}$ stretching vibrational mode in graphite sheets and $\mathrm{D}$ band at around $1337 \mathrm{~cm}^{-1}$ is related to scattering from amorphous carbon and structural defects present in SWCNTs. In addition, a 2D-band occurs at $2663 \mathrm{~cm}^{-1}$ which is the second harmonic of D-band. The radial breathing modes (RBMs) about $280 \mathrm{~cm}^{-1}$ attributed to the collective breathing vibration of the entire SWCNTs, indicating little or no tube damage. Also, the high intensity of RBM in Raman spectrum of 3 reveals the nanotube diameters are below $2 \mathrm{~nm}$ (figure S2). ${ }^{19}$

Moreover, Raman bands of f-SWCNTs/diazo 3 show small frequency shift and large intensity changes in comparison with 4-hydroxy phenyl-SWCNTs $\mathbf{2}$. It is evident that the covalent attachment of diazo compound to precursor 2 results in the appearance of Raman new bands for f-SWCNTs/diazo 3. Down-shift of RBM mode for the main product 3 related to the decreased interaction between carbon nanotubes (debundling) through more functional groups on it. Also, the reduction of $\mathrm{D} / \mathrm{G}$ ratio in primary 4-hydroxy phenyl-SWCNTs 2 confirmed the higher purity of it in comparison with f-SWCNTs/diazo 3.

3.1d SEM images: Structural characterization of the pristine nanotubes and f-SWCNTs/diazo 3 was performed using scanning electron microscopy (SEM).
We present the images of pristine SWCNTs in figure $3 \mathrm{a}$. They exhibit the microscopic fibre-like ropes which appear to be flexible and the fibre-like entities having typical diameters about 35 nanometers. As can be seen after functionalization (figure $3 \mathrm{~b}$ ), nanotubes are dispersed better than as-received SWCNTs and azo pigment clusters are attached to nanotube surfaces which leads to an increase of the intershell spacing as well.

3.1e ${ }^{13} C-{ }^{1} H$ HSQC-NMR spectra: An essential and logical method in exploring the manifesting of covalent attachment would be nuclear magnetic resonance (NMR) spectra. So, the chemical structure of f-SWCNTs/diazo 3 was investigated by ${ }^{1} \mathrm{HNMR}$, ${ }^{13} \mathrm{CNMR}$ and ${ }^{13} \mathrm{C}-{ }^{1} \mathrm{H}$ HSQC analyses. As can be seen in table 1, the ${ }^{1} \mathrm{HNMR}$ spectrum of it in DMSO$d_{6}$ has displayed a singlet at $10.97 \mathrm{ppm}$ which is arising from hydroxyl proton with intramolecular $\mathrm{H}$ bonding. The protons in toluene moiety were resonated at 7.89 and $7.38 \mathrm{ppm}$ as doublets $\left({ }^{3} \mathrm{~J} \cong 8 \mathrm{~Hz}\right)$. Also, the aromatic protons in phenolic ring have been appeared at $7.56 \mathrm{ppm}$ as singlet, at 7.22 and $6.95 \mathrm{ppm}$ as doublets $\left({ }^{3} J \cong 8 \mathrm{~Hz}\right)$. The singlet proton at $\delta=$ $7.56 \mathrm{ppm}$ shows the arrangement of diazo component. The most important characteristic signals in ${ }^{1} \mathrm{HNMR}$ of f-SWCNTs/diazo 3 are the allylic protons connecting to the nanotubes as a singlet at $2.52 \mathrm{ppm}$ and two methyl groups connecting to the carbon nanotube side walls and benzene ring at 2.40 and $2.28 \mathrm{ppm}$.

The ${ }^{13}$ CNMR spectrum of f-SWCNTs/diazo 3 in DMSO- $d_{6}$ (table 1) exhibited some peaks between 118 and $152 \mathrm{ppm}$ readily recognized as arising from aromatic and olefinic carbons resonances. Also, methyl groups have been appeared at 21.04, $19.96 \mathrm{ppm}$, respectively. Nanotube allylic carbons were also observed being overlapping with the signals of solvent, but ${ }^{13} \mathrm{C}$ ${ }^{1} \mathrm{H}$ HSQC spectroscopy (figure 4) shows their relation to the corresponding protons $\left(\delta \mathrm{c} / \delta_{H} 40.0 / 2.5 \mathrm{ppm}\right)$. 


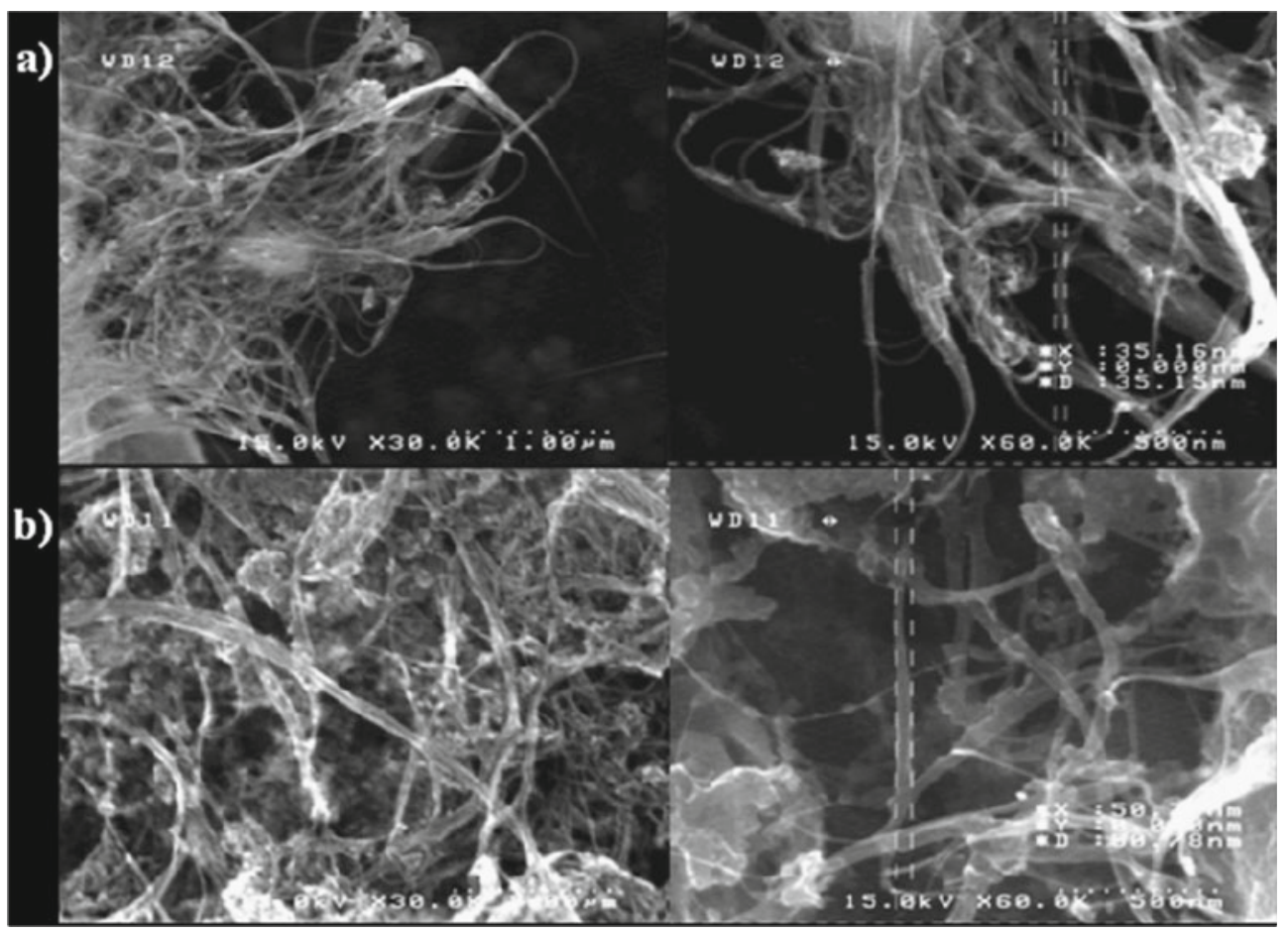

Figure 3. SEM image of (a) pristine nanotubes (b) f-SWCNTs/diazo 3.

Table 1. NMR chemical shifts (ppm) of f-SWCNTs/diazo 3 and ${ }^{13} \mathrm{C}-{ }^{1} \mathrm{H}$ HSQC assignment.

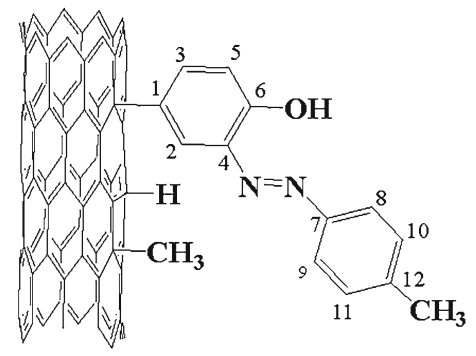

\begin{tabular}{|c|c|c|c|c|c|}
\hline & ${ }^{1} \mathrm{HNMR}$ & ${ }^{1} \mathrm{HNMR}$ & ${ }^{13} \mathrm{CNMR}$ & ${ }^{13} \mathrm{CNMR}$ & HSQC \\
\hline $\mathrm{C}_{1}$ & - & - & 137.79 & 137.40 & - \\
\hline $\mathrm{C}_{2}, \mathrm{H}_{2}$ & $7.56 \mathrm{~s}$ & $7.76 \mathrm{~s}$ & 123.13 & 133.18 & $123.1 / 7.6$ \\
\hline $\mathrm{C}_{3}, \mathrm{H}_{3}$ & $6.95 \mathrm{~d}$ & $6.95 \mathrm{~d}$ & 117.89 & 118.20 & $117.9 / 6.9$ \\
\hline $\mathrm{C}_{4}$ & - & & 152.13 & 151.22 & - \\
\hline $\mathrm{C}_{5}, \mathrm{H}_{5}$ & $7.22 \mathrm{~d}$ & $7.17 \mathrm{~d}$ & 134.10 & 134.28 & $134.1 / 7.2$ \\
\hline $\mathrm{C}_{6}$ & - & - & 141.44 & 142.55 & - \\
\hline $\mathrm{C}_{7}$ & - & - & 149.46 & 149.18 & - \\
\hline $\mathrm{C}_{8}, \mathrm{H}_{8}-\mathrm{C}_{11}, \mathrm{H}_{11}$ & $7.89,7.38 \mathrm{~d}$ & $7.79,7.34 \mathrm{~d}$ & $129.94,122.53$ & $130.42,122.55$ & $\begin{array}{l}129.9 / 7.4 \\
122.5 / 7.9\end{array}$ \\
\hline $\mathrm{C}_{12}$ & - & - & 128.57 & 129.55 & - \\
\hline $\mathrm{CH}_{3}$ & $2.40 \mathrm{~s}$ & $2.41 \mathrm{~s}$ & 21.04 & 21.92 & $21.0 / 2.4$ \\
\hline $\mathrm{OH}$ & 10.97 & 12.77 & - & - & - \\
\hline $\mathrm{SWCNTs} \mathrm{CH}_{3}$ & $2.28 \mathrm{~s}$ & $2.38 \mathrm{~s}$ & 19.96 & 20.72 & $19.9 / 2.3$ \\
\hline SWCNTs-CH & $2.52 \mathrm{~s}$ & $2.98,2.91 \mathrm{~s}$ & - & 39.42 & $40.0 / 2.5$ \\
\hline SWCNTs- $_{\mathrm{sp} 3}$ & - & - & - & 38.12 & - \\
\hline
\end{tabular}

d: doublet; s: singlet 

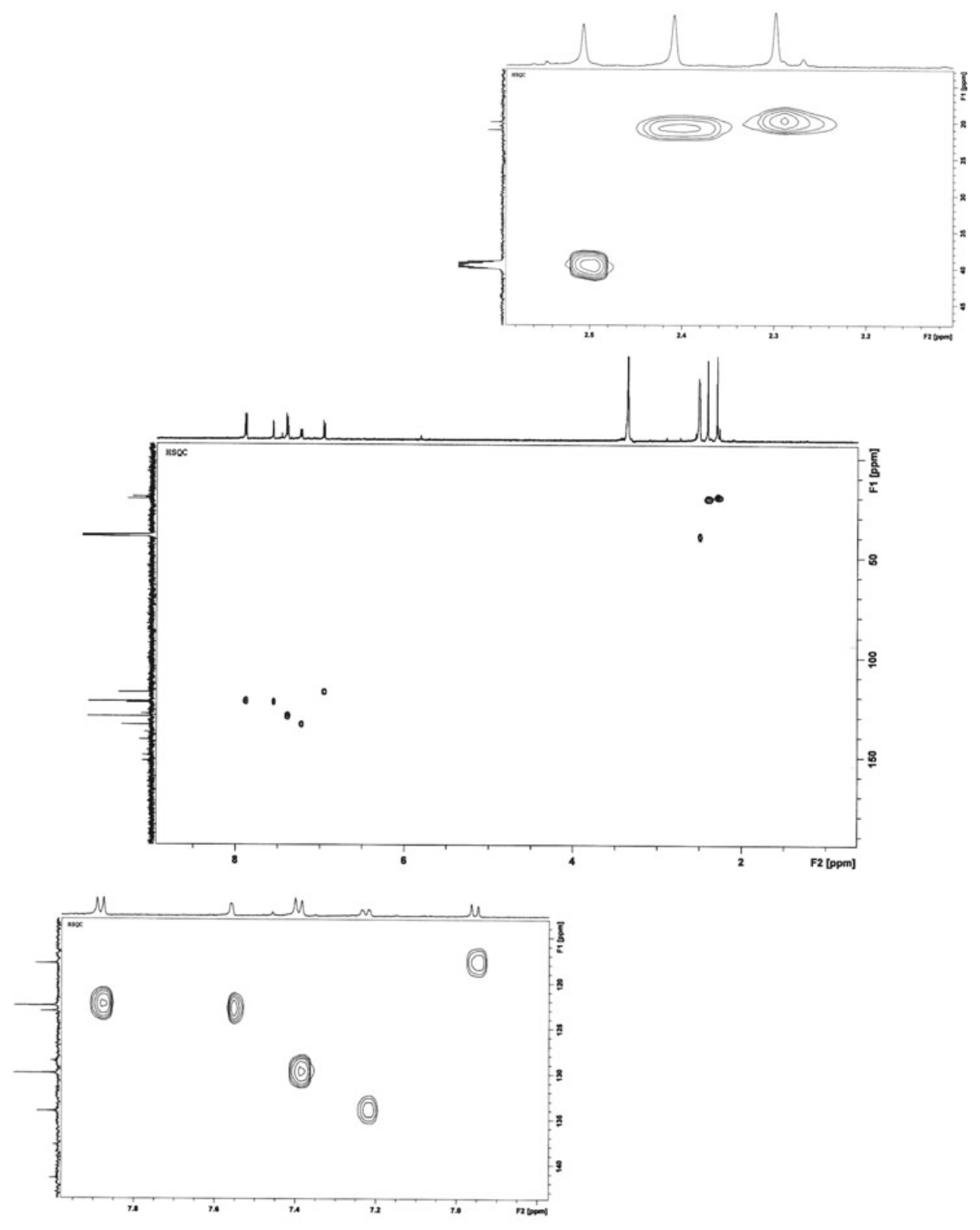

Figure 4. ${ }^{13} \mathrm{C}-{ }^{1} \mathrm{H}$ HSQC-NMR spectrum of f-SWCNTs/diazo 3.

The ${ }^{13} \mathrm{C}-{ }^{1} \mathrm{H}$ HSQC spectrum which has been presented in figure 4 has a projection onto the F2 axis which corresponds to the normal ${ }^{1} \mathrm{H}$ spectra and the projection onto the $\mathrm{F} 1$ axis corresponds to a normal ${ }^{13} \mathrm{C}$ spectrum, but with the quaternary carbons missing. It shows the region $\delta \mathrm{c} / \delta_{H} 0-200 / 2-8 \mathrm{ppm}$. The existence of methyl protons which have attached to the carbon nanotube walls was evident by this technique $\left(\delta \mathrm{c} / \delta_{H}\right.$ 19.9-21.0/2.1-2.3 ppm). Also, the remaining protons which are related to the region of aromatic carbons $\left(\delta \mathrm{c} / \delta_{H} 118.0-134.1 / 6.9-7.9 \mathrm{ppm}\right)$ were specified in table 1 .

Furthermore, the ${ }^{1} \mathrm{HNMR}$ and ${ }^{13} \mathrm{CNMR}$ of final product 3 in $\mathrm{CDCl}_{3}$ confirm the allylic protons and carbons of SWCNTs. As reported in table 1, the same signals were characterized by these spectrums with a bit shift. But the $\mathrm{sp}^{3}$ carbons on the nanotubes have appeared better than before (38.12 and $39.42 \mathrm{ppm}$ ).

\section{Conclusion}

The chemical functionalization of carbon nanotubes is an attractive target as it can improve the unique properties of CNTs to be coupled to other types of materials. In spite of extensive investigation on the non-covalent functionalization of multi-walled carbon nanotubes (MWCNTs), the reported works about covalent functionalization of single-walled carbon nanotubes is still scant. So, we focus on the covalent attachment of diazo 
functional group to the surfaces of single-walled carbon nanotubes through a simple approach. In conclusion, we could prepare dark brown SWCNTs with the ability to produce colour. The products obtained were characterized by UV-vis-NIR, FTIR, Raman and SEM technique and the chemical shift of the allylic protons connecting to the side walls of carbon nanotubes have been assigned by ${ }^{13} \mathrm{C}-{ }^{1} \mathrm{H}$ HSQC-NMR spectroscopy for the first time.

\section{Supporting material}

Supplementary material given as figures S1-S2 can be seen online www.ias.ac.in/chemsci.

\section{Acknowledgements}

Authors thank the Iranian Nano Technology Initiative Council for the support and the Central Tehran Branch of Islamic Azad University for providing equipment facility in research laboratory.

\section{References}

1. Avouris P, Chen Z H and Perebeinos V 2007 Nat. Nanotechnol. 2605
2. Wong E W, Sheehan P E and Lieber C M 1997 Science 2771971

3. Iijima S 1991 Nature 35456

4. Zhao V and Stoddart J F 2009 Acc. Chem. Res. 421161

5. Liu P 2005 Eur. Pol. J. 412693

6. Gup R, Giziroglu E and Kirkan B 2007 Dyes Pigments. 7340

7. Cui Y, Wang M, Chen L and Qian G 2004 Dyes Pigments. 6243

8. Maradiya H R and Patel V S 2001 J. Braz. Chem. Soc. 12710

9. Yildiz E and Boztepe H 2002 Turk. J. Chem. 26897

10. Burlov A S, Uraev A I, Lysenko K A, Chigarenko G G, Ponomarenko A G and Matuev P V 2006 Russ. J. Coor. Chem. 32686

11. Chigrinov V, Prudnikova E, Kozenkov V and Kwok H 2002 Liq. Crys. 291321

12. Andrade A A, Yamaki S B, Misoguti L, Zilio S C, Atvars T D Z and Oliveria Jr O N 2004 Opt. Mater. 27441

13. Klajnert B and Bryszewska M 2001 Acta. Biochim. Polonica. 48199

14. Carofiglio T, Fregonese C, Mohr G J, Rastrelli F and Tonellato U 2006 Tetrahedron 621502

15. Chio M T M, Li P P S and Ng D N P 2000 Tetrahedron 563881

16. Chen Z, Li X Y, Ngai T, Wu C and Ng D K P 2001 Langmuir 177957

17. Chiang I W 2001 J. Phys. Chem. B. 1058297

18. Liu J, Zubiri M R I, Dossot M, Vigolo B, Hauge R H and Fort Y 2006 Chem. Phys. Lett. 43093

19. Belin T and Epron F 2005 Mater. Sci. Eng. B. 119105 